Beiträge zur Tabakforschung International/

Contributions to Tobacco Research

Volume $27 \cdot$ No. $7 \cdot$ September 2017

DOI: $10.1515 /$ cttr-2017-0013

\title{
Assessment of Nicotine Exposure From Active Human Cigarette Smoking Time *
}

\author{
by \\ Xavier Cahours, Rémi Julien, Thomas Verron, and Stéphane Colard \\ SEITA, Imperial Tobacco Ltd., 48, rue Danton, 45404 Fleury-les-Aubrais, France
}

\section{SUMMARY}

The burning of a cigarette is a series of consecutive sequences of both passive and active burnings when a smoking cycle is applied to the cigarette. A previous study, using a smoking machine, showed that cigarette nicotine yields are dependent linearly on the difference between the time of smouldering (passive burning) and the time of smoking (active burning). It is predicted that the smoker's nicotine yield increases when the intensity of smoking increases, i.e., when the time to smoke a cigarette (smoking time) decreases. Note that observations made on machines might not be comparable to human behaviours. The aim of this study was to determine whether nicotine mouth-level exposure could be predicted through measurement of human smoking time. A smoking behaviour study was conducted to compare human smoking nicotine yields obtained from both filter tip analysis and the cigarette burning time model. Results showed that smokers' exposure to the smoke depends essentially on the speed at which the cigarette is smoked. An increase in human smoking intensity, resulting in a decrease in smoking time, generates an increase in smoke exposure, whatever the puff number, puff duration, puff volume and filter ventilation (open or blocked). The association of a machine smoking yield with a corresponding smoking time, and the time taken by a consumer to smoke the cigarette would provide information on the exposure to smoke constituents in a simple and effective manner. [Beitr. Tabakforsch. Int. 27 (2017) 125-134]

\section{ZUSAMMENFASSUNG}

Das Abbrennen einer Zigarette besteht aus einer Abfolge von Sequenzen passiver und aktiver Verbrennung, wenn die Zigarette einem Rauchzyklus ausgesetzt wird. In einer früheren Studie wurde mithilfe einer Rauchmaschine gezeigt, dass Zigaretten-Nikotinausbeuten linear abhängig sind von der Differenz zwischen der Glimmzeit (passive Verbrennung) und der Rauchzeit (aktive Verbrennung). Es wird vorhergesagt, dass sich die Nikotinausbeute für den Raucher erhöht, wenn die Intensität des Rauchens zunimmt, das heißt, wenn die Zeit zum Abrauchen einer Zigarette (Abrauchzeit) abnimmt. Es sei darauf hingewiesen, dass Beobachtungen an Maschinen möglicherweise nicht mit menschlichen Verhaltensweisen vergleichbar sind. Ziel dieser Studie war es zu bestimmen, ob die Nikotinexposition im Mundraum anhand einer Messung der menschlichen Abrauchzeit vorhergesagt werden kann. Es wurde eine Studie zum Rauchverhalten durchgeführt, um beim menschlichen Rauchen die Nikotinausbeuten aus der 
Filterspitzenanalyse mit denen des Zigaretten-BrennzeitModells zu vergleichen. Die Ergebnisse zeigten, dass die Rauchexposition des Rauchers im Wesentlichen von der Geschwindigkeit abhängt, mit der die Zigarette geraucht wird. Eine Zunahme der menschlichen Rauchintensität, die zu einer Abnahme der Abrauchzeit führt, resultiert in einer Steigerung der Rauchexposition - unabhängig von Zugzahl, Zugdauer, Zugvolumen und Filterventilation (durchlässig oder undurchlässig). Die Assoziation einer maschinellen Rauchausbeute mit einer entsprechenden Abrauchzeit sowie der Zeit, die ein Mensch für das Rauchen einer Zigarette benötigt, würde auf einfache, effektive Weise Angaben zur Exposition gegenüber Rauchbestandteilen liefern. [Beitr. Tabakforsch. Int. 27 (2017) 125-134]

\section{RESUME}

La combustion d'une cigarette est le résultat d'une succession de deux phases de combustion dites active et passive qui est fonction d'un régime de fumage. Récemment une étude, basée sur un régime de fumage machine, a montré que le niveau de nicotine dans la fumée est linéairement proportionnel à la différence de temps entre la combustion passive et la combustion active. On peut donc en déduire que le fumeur augmente son exposition à la nicotine quand il est intensifie son régime de fumage, c'est-à-dire quand il diminue son temps pour fumer sa cigarette. Toutefois les observations obtenues à partir de machines ne sont pas forcément transposables au comportement humain. L'objectif de cette étude est de déterminer si l'exposition à la nicotine peut être prédite à partir des temps de consommation de cigarettes mesurés sur des individus. Une étude du comportement du fumeur a été conduite afin de comparer les rendements de nicotine de fumeurs obtenus à partir d'analyses du filtre et d'un modèle mathématique « cigarette burning time model ». Les résultats ont montré que l'exposition à la fumée dépend principalement de la vitesse à laquelle la cigarette est fumée. Une augmentation de l'intensité du fumage, induit une diminution du temps de fumage et par conséquent génère une augmentation de l'exposition à la fumée, et ce quel que soit le nombre de bouffées, la durée des bouffées, le volume de bouffées ou encore le taux de ventilation filtre. Finalement l'association d'un régime de fumage machine avec un temps de fumage, complété avec le temps de consommation d'une cigarette par individu fourniraient une information simple et efficace sur le niveau d'exposition d'un consommateur aux constituants de la fumée. [Beitr. Tabakforsch. Int. 27 (2017) 125-134]

\section{INTRODUCTION}

Many approaches have been used to determine smokers' exposure to cigarette smoke constituents. The most effective method is the measurement of biomarkers, which has the advantage of estimating independently the subjects' smoking behaviour, i.e., number of cigarettes smoked, puffing pattern, mouth spill and inhalation pattern (1-4). However, biomarker assessment is invasive, necessitates sophisticated equipment and often includes complex sample preparation steps prior to analysis. Other noninvasive methods have been developed for estimating cigarette smoke exposure to obtain useful information, often in a more easily accessible form. For example, the number of cigarettes smoked per day (CPD) or over a longer period of time using the Brinkman index (number of cigarettes smoked per day multiplied by number of years of smoking) (5) or pack years (6) can be used as a potential proxy for exposure to tobacco smoke constituents. The number of cigarettes smoked is the most frequently used indicator of exposure to cigarette smoke in epidemiological studies, but it may be inaccurate. For instance, the number of cigarettes smoked per day explains less than half of the variance in saliva cotinine (7). The remaining variance is explained by variations in puffing topography (e.g., number of puffs, puff duration and volume) and smoking topography (e.g., depth and duration of inhalation). Measurement of puffing topography (puff volume, duration, and frequency) using a smoking topography device, followed by accurate duplication of this record using a specialised smoking machine, was also used to estimate the human smoking yields (HSY) or mouth-level exposure (MLE) yields to mainstream cigarette smoke (8). Nevertheless, it is possible that the artificial feel of smoking topography devices alters puffing topography and/or smoking topography. To determine more accurately MLE to mainstream cigarette smoke in natural settings, the analysis of spent cigarette butts has been described as the least invasive of the methods mentioned above (9-12). The basic principle is that the amount of "tar" and nicotine that emerge from the filter are proportional to the amounts trapped in the part-filter section. Consequently, human smoke yields may be estimated by comparison of the nicotine content of cigarette filter (butt nicotine) extracts from consumer smoked cigarettes with those from machine smoked cigarettes for which the smoke yield (pad nicotine) is determined. ST.CHARLES et al. described in detail a methodology based on 10-mm mouth end section analysis to avoid issues with filter ventilation, that is the so-called Part-Filter method (13).

Various smoking behaviour studies have estimated the HS yield for nicotine and "tar" using filter analysis $(9,14,15)$. The influence of cigarette design parameters or ingredients on HS-Nicotine and "tar" have been reported $(16,17)$. Recently, the applicability of HS yield for constituents other than "tar" and nicotine have been studied such as TSNA (18) or $\mathrm{B}(a) \mathrm{P}(19-21)$. A particular advantage of the approach is that data from the collected butts relate to smoking behaviour of the subjects in their usual environment and on their own schedules. The analysis of discarded cigarette filter butts allows measurements on a cigarette-tocigarette basis, variations in exposure between cigarettes can be analysed on a fine scale rather than the time-averaged information that biomarker studies provide. Cigarette butt collection is much less intrusive than collection of body fluids, so recruitment of subjects for studies and compliance may be improved. However, due to large quantities of cigarette butts generated from smoking studies, the collection of cigarette butts over time and the importance of the storage conditions, this Part-Filter method requires well-organized sample management. Moreover, due to brand variability, different calibration 
curves are needed for each brand variant. An alternative to this Part-Filter method would be the use of cigarette smoking time (ST), conventionally defined as the time a cigarette burns during smoking. This time can be affected by cigarette characteristics and smoking behaviour. LIANG et al. (22) examined the relationship of ST and exposure to nicotine and carbon monoxide of adult smokers in a controlled clinical study. They showed that ST had a significant influence on levels of nicotine exposure.

The purpose of our study was to determine whether HSNicotine yields can be easily predicted from human smoking time. The approach taken for this study was to compare the nicotine yield of human-smoked cigarettes (mouth-level exposure) measured with two different methods using the filter analysis method and smoking time. With a good correlation between the methods, future studies on smoker exposure could use the simpler timerecording method rather than collecting cigarette butts for analytical measurement. The secondary objective was to compare smoking time and MLE exposure to nicotine.

\section{EXPERIMENTAL}

\section{Description of the products}

Two commercial products (A and B) having different nicotine levels under ISO smoking regime were used in this study (Table 1).

\section{Estimation of human smoking nicotine yields}

HS-Nicotine yields were estimated using two independent methods, the Part-Filter method and the smoking time method. Figure 1 illustrates a flowchart of the study design from smoking to HS-Nicotine yields estimation.

Table 1. Cigarette characteristics.

\begin{tabular}{llcr|r}
\hline Cigarette description & & Product A & Product B \\
\hline Blend style & & \multicolumn{3}{c}{$\begin{array}{c}\text { US blend } \\
\text { Cellulose acetate }\end{array}$} \\
Filter type & & & 83 & 21 \\
Cigarette length & $(\mathrm{mm})$ & 27 & 0 \\
Filter length & $(\mathrm{mm})$ & 52 & 130 \\
Filter ventilation & $(\%)$ & 104 & 673 \\
Pressure drop & $(\mathrm{mm} \mathrm{WG})$ & 546 & 10.0 \\
Tobacco weight & $(\mathrm{mg})$ & 3.3 & 0.9 \\
NFDPM & $(\mathrm{mg} / \mathrm{cig})($ under ISO) & 0.4 & 10.5 \\
Nicotine & $(\mathrm{mg} / \mathrm{cig})$ (under ISO) & 4.6 & 25.5 \\
Carbon monoxide & $(\mathrm{mg} / \mathrm{cig})$ (under ISO) & 10.9 & 2.0 \\
NFDPM & $(\mathrm{mg} / \mathrm{cig})$ (under Cl) & 0.98 & 23.1 \\
Nicotine & $(\mathrm{mg} / \mathrm{cig})$ (under Cl) & 13.6 & \\
Carbon monoxide & $(\mathrm{mg} / \mathrm{cig})$ (under Cl) & & \\
\hline
\end{tabular}

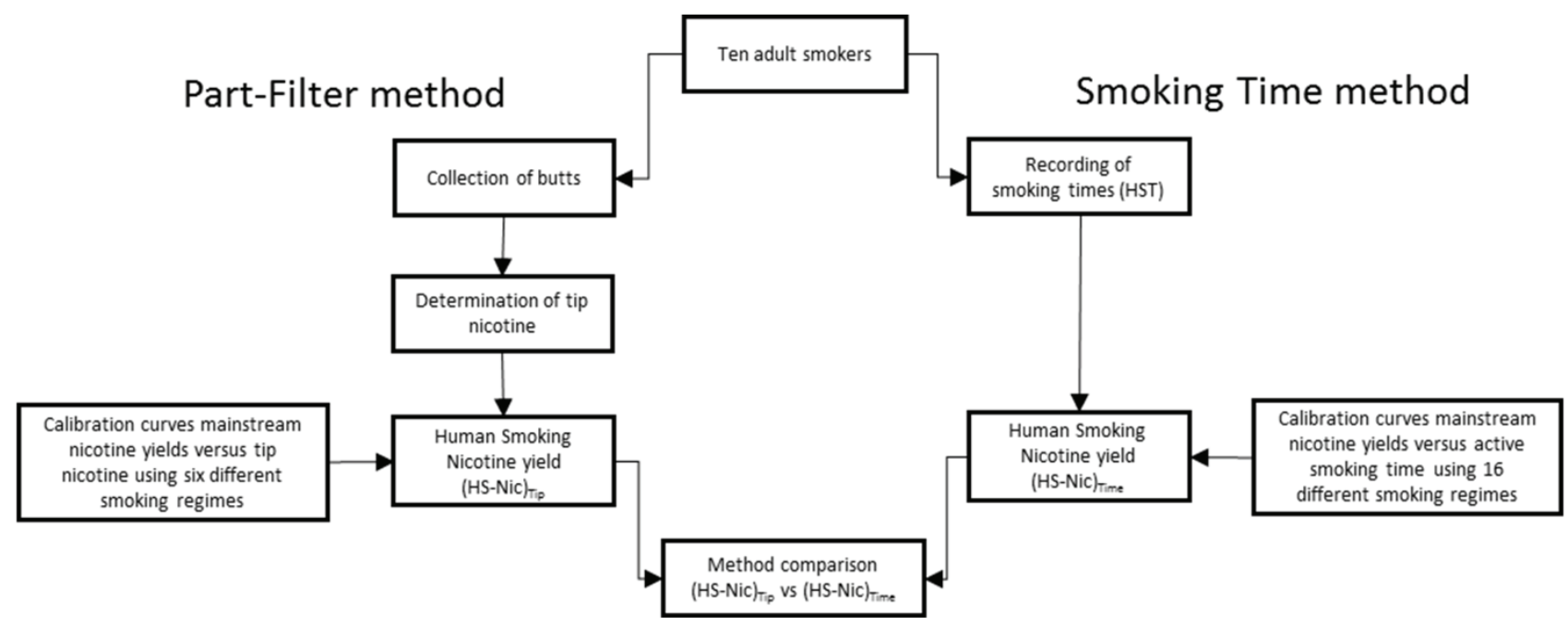

Figure 1. Flowchart of experiments used to evaluate HS-Nicotine yields. 


\section{Estimation of HS-Nicotine yields using Part-Filter method}

The first estimation was obtained using the Part-Filter method $(10,23)$. This method is applicable to the estimation of human smoke exposure to nicotine and "tar" using linear calibration regression equations between mainstream smoke yields and corresponding analytes from part-filter extracts. In our study, calibration regressions were generated by determining machine smoking nicotine (MS-Nic) yields against filter tip nicotine from analysis of part-filters using six smoking regimes covering a wide range of typical human smoking behaviour parameters (24) (Table 2). This procedure was duplicated on a different day to provide independent replicate data. Two sets of unsmoked filters were also included as blanks.

The Cambridge filter pads were extracted and analysed for nicotine content (25). Tip data for nicotine was obtained by analysis of the $10-\mathrm{mm}$ part filters using the CORESTA Recommended Method No. 9 (26).

HS-Nicotine yields, or mouth-level exposure to nicotine for smokers were assessed with the linear regression equation obtained by plotting the MS-Nic yields yield versus the tip nicotine data obtained during calibration smoking and the measured smoker tip nicotine values. Consequently, all butts (tips) of cigarettes smoked were collected and analysed to measure tip nicotine and to estimate with the PartFilter method the HS-Nicotine yields, (HS-Nic) Tip $_{\text {. Calibra- }}$ tions for deriving regression equations were necessary for each of the two products investigated.

Table 2. Smoking regimes used for the calibration curves relating mainstream nicotine yields to filter tip nicotine.

\begin{tabular}{l|c|c|c}
\hline $\begin{array}{l}\text { Smoking } \\
\text { regime }\end{array}$ & $\begin{array}{c}\text { Puff volume } \\
(\mathrm{mL})\end{array}$ & $\begin{array}{c}\text { Puff duration } \\
(\mathrm{s})\end{array}$ & $\begin{array}{c}\text { Puff interval } \\
(\mathrm{s})\end{array}$ \\
\hline 1 & 17.5 & 2 & 60 \\
2 & 35 & 2 & 60 \\
3 & 55 & 2 & 60 \\
4 & 55 & 2 & 30 \\
5 & 70 & 2 & 60 \\
6 & 70 & 2 & 20 \\
\hline
\end{tabular}

\section{Estimation of human smoking nicotine yields using smoking time}

The second estimation was based on the linear relationship between the smoke nicotine and the active smoking time (smouldering time minus cigarette smoking time) described previously by this group of authors $(27,28)$. We showed that MS-Nic and MS-"tar" yields among other smoke constituents are linearly related to the difference between the smouldering time (cigarette combustion with no puffing) and the machine smoking time, MST (cigarette combustion with puffing). We concluded that the obtained correlations provide an approach to relate yields from one smoking regime to another. In our study, relationships were evaluated between measured mainstream nicotine yields and the difference between smouldering and smoking times with filter ventilation open or blocked under 16 different smoking regimes (Table 3). With these linear regression equations it was possible to assess the HS-Nicotine yields (HS-Nic) $_{\text {Time }}$ using the human smoking time (HST) recorded during our experiments. One day before the study, all smokers were trained on how to monitor and record their smoking time. The start of HST coincided with the lighting of the cigarette and the end of HST corresponded to the time when the lit part of the cigarette reached $3 \mathrm{~mm}$ from the filter tipping (this was marked with a pencil line). The smokers were asked to smoke in their usual way but had to stop puffing before the burning zone of the cigarette reached the 3-mm line. All measurements were supervised by the study staff to ensure accuracy and compliance with the study protocol. Ten subjects participated in experimental sessions in a smoking room with controlled temperature, humidity and ventilation.

Table 3. Smoking regimes used for the calibration curves mainstream nicotine yields versus active smoking time (time of smouldering minus time of smoking), with filter ventilation open or blocked.

\begin{tabular}{l|c|c|c}
\hline $\begin{array}{l}\text { Smoking } \\
\text { Regime }\end{array}$ & $\begin{array}{c}\text { Puff volume } \\
(\mathrm{mL})\end{array}$ & $\begin{array}{c}\text { Puff duration } \\
(\mathrm{s})\end{array}$ & $\begin{array}{c}\text { Puffing period } \\
(\mathrm{s})\end{array}$ \\
\hline 1 & 17.5 & 2 & 60 \\
2 & 17.5 & 2 & 40 \\
3 & 17.5 & 2 & 30 \\
4 & 17.5 & 2 & 20 \\
5 & 35 & 2 & 60 \\
6 & 35 & 2 & 40 \\
7 & 35 & 2 & 30 \\
8 & 35 & 2 & 20 \\
9 & 55 & 2 & 60 \\
10 & 55 & 2 & 40 \\
11 & 55 & 2 & 30 \\
12 & 55 & 2 & 20 \\
13 & 70 & 2 & 60 \\
14 & 70 & 2 & 40 \\
15 & 70 & 2 & 30 \\
16 & 70 & 2 & 20 \\
\hline
\end{tabular}

\section{RESULTS AND DISCUSSION}

Figure 2 shows the HST measured with the ten volunteers smoking the cigarette brand A ten times over several days. The mean HST ranged from 2.96 to 5.85 min with coefficients of variation from 0.6 to $12.5 \%$. The time spent for smoking was relatively constant for each smoker. Only one smoker smoked quite rapidly, but most of them smoked their cigarette between 5 and $6 \mathrm{~min}$. In the conditions of the experiment, the maximum smoking time defined by the smouldering time for the studied cigarette was $7.2 \mathrm{~min}$.

The smouldering time is brand-dependent, according to the tobacco blend and cigarette paper, but it is also influenced by the moisture of the tobacco rod. To highlight the effect of tobacco moisture on free smouldering time and therefore on HS-Nicotine yields prediction, four smokers were asked to smoke the product A stored under two conditions of temperature and relative humidity $(\mathrm{RH}), 20^{\circ} \mathrm{C} / 60 \% \mathrm{RH}$ and $25^{\circ} \mathrm{C} / 70 \% \mathrm{RH}$, respectively. Participants were asked to record their smoking time and to collect cigarette butts for filter tip analysis, i.e., $(\mathrm{HS}-\mathrm{Nic})_{\mathrm{Tip}}$. 


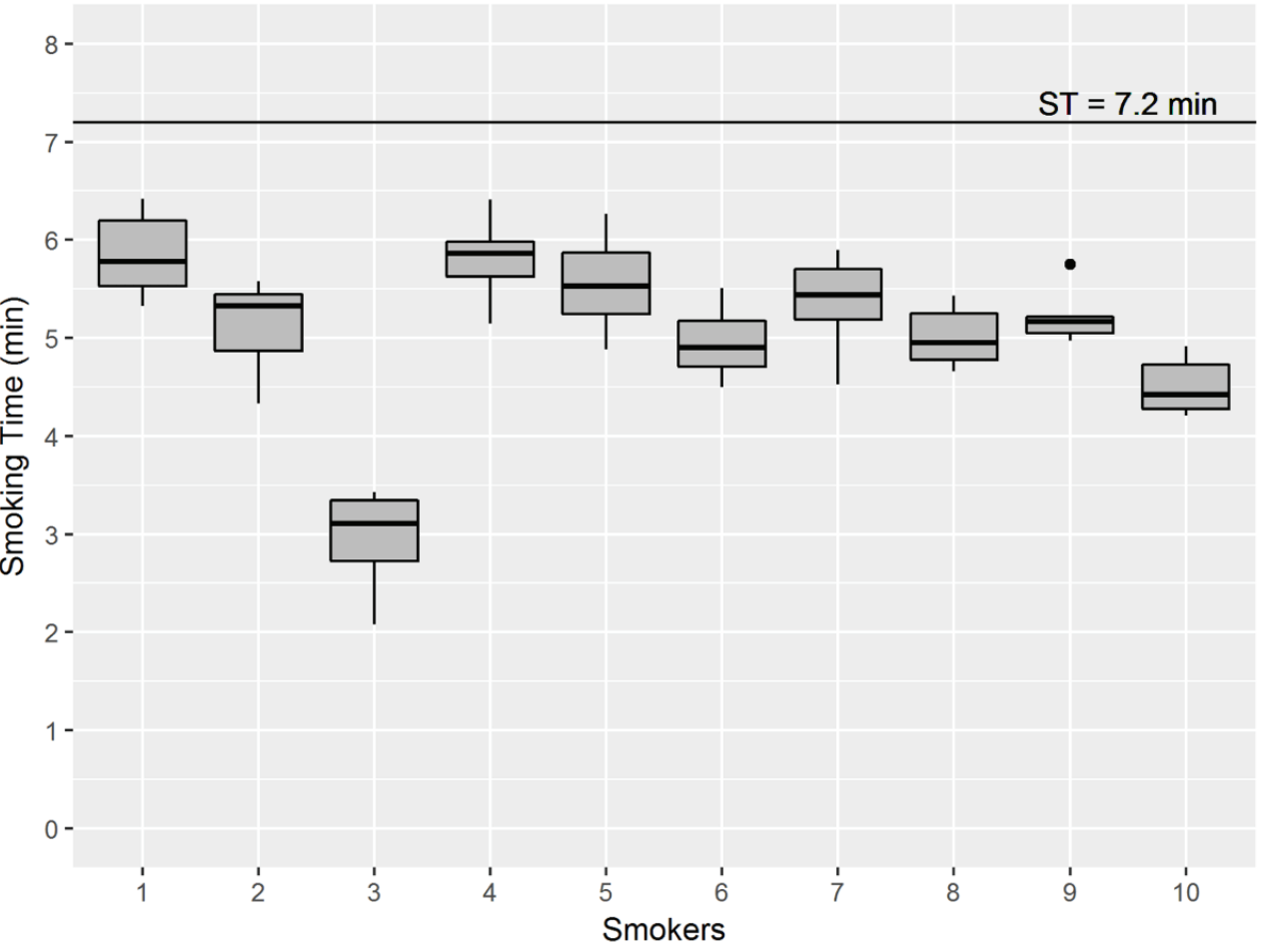

Figure 2. Human smoking times obtained with a panel of ten consumers smoking the product $A$.

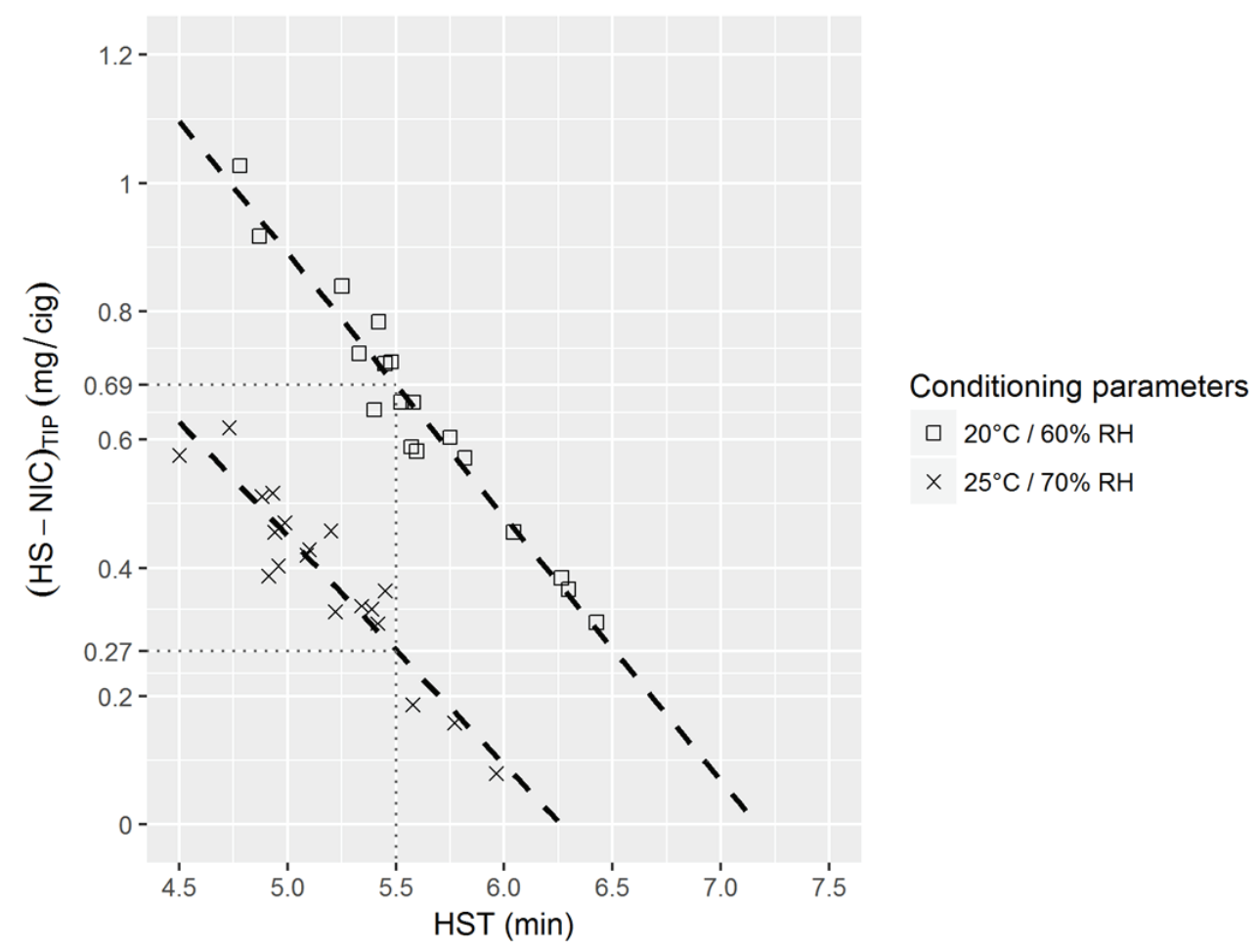

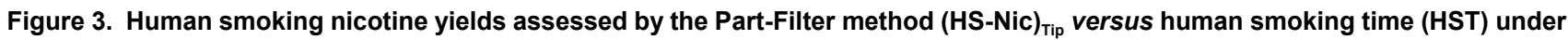
two ambient air conditioning parameters for product $A$. 


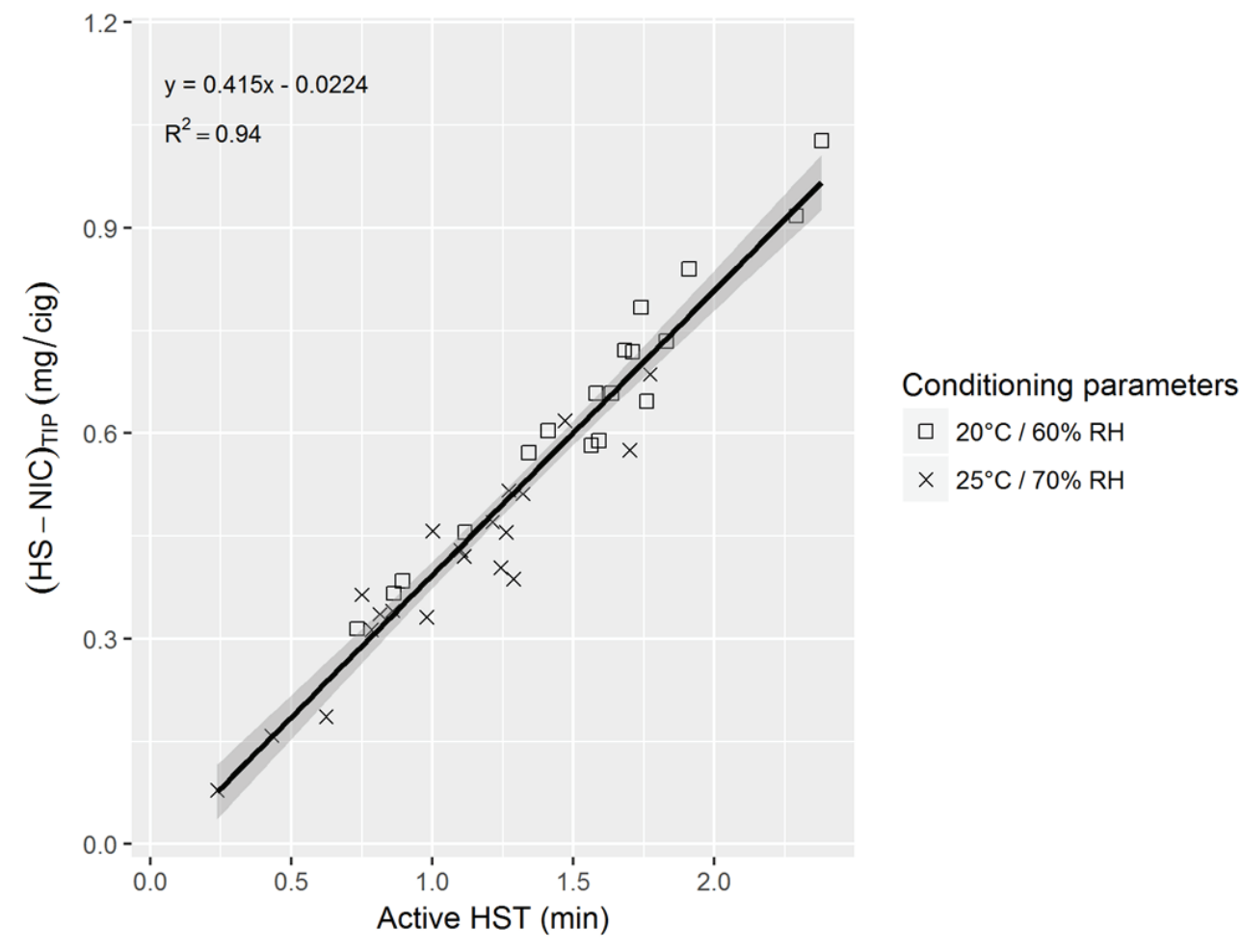

Figure 4. Human smoking nicotine yields assessed by the Part-Filter method (HS-Nic) $)_{\mathrm{Tip}}$ versus active human smoking time (Active HST) under two cigarette conditioning parameters.

Figure 3 illustrates the relationship between HST and (HSNic $)_{\text {Tip }}$ which was determined using Part-Filter method. Each smoker repeated the experiment five times. Two groups of points corresponding to the two conditioning parameters $20^{\circ} \mathrm{C} / 60 \% \mathrm{RH}$ and $25^{\circ} \mathrm{C} / 70 \% \mathrm{RH}$, respectively, are clearly observed. This is due to a difference in free smouldering time caused by a difference in tobacco moisture. Consequently, the estimation of exposure from the smoking time can be significantly dissimilar according to the storing condition of cigarettes. In our experiment, a HST of 5.5 min gave a nicotine mouth level exposure of $0.27 \mathrm{mg}$ or $0.69 \mathrm{mg}$ per cigarette depending on the conditioning parameters.

Using Active HST, corresponding to the free smouldering time minus the HST, a good correlation was obtained whatever the conditioning parameters (Figure 4).

Based on these experiments, Active HST may be considered a valid approach to assess the HS-Nicotine yield. Figure 5 shows the agreement between the two methods allowing the assessment of HS-Nicotine, 1/ the model machine smoke nicotine yield versus active machine smoking time; 2/ the Part-Filter method.

The linear regression passing through zero with a slope close to one and the good coefficient of correlation of 0.98 , demonstrates that the two methods are aligned on the range from 0 to $2 \mathrm{mg} / \mathrm{cig}$.

In 2015, we reported that the correlations observed between yields and mass of tobacco actively burnt provided a way to link yields from one smoking regime to another and confirmed that yields determined from one regime were sufficient to establish the relationships between yields and smoking intensity. Then, the model machine smoke nicotine yield versus active machine smoking time allowing the assessment of human smoking yields from Active HST can be used by applying only one smoking regime. The alignment of human versus machine smoke yields from emissions determined under a single machine smoking regime was checked. HST of five smokers was measured to estimate (HS-Nic) $)_{\text {Time }}$ using a calibration model linking smoke nicotine to active machine cigarette smoking time determined under the Canada Intense (CI) smoking regimes only. In parallel, the cigarette butts were collected and analysed to measure filter-tip nicotine in order to assess the

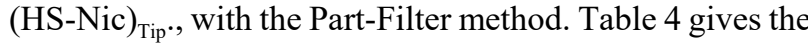
estimations obtained with both methods.

The two methods gave similar results of HS-Nicotine yield whatever the product. For product A (ventilated product), the accuracy between the two methods ranges from $91 \%$ to $103 \%$ and for product B (non-ventilated product) from $94 \%$ to $99 \%$, using the Part-Filter Method as the reference.

It can be concluded that, based on the good correlation between both methods, active human smoking time may be considered as a surrogate marker of overall cigarette smoke exposure over a short term period.

Using only one smoking machine, the mouth level exposure can be estimated from human smoking time. The application of a single regime presents the benefit of reserving laboratory resources for more complex chemistry and other assessments.

Figure 6 shows the relationship between smoke nicotine and active smoking time obtained with machine smoking regimes $(n=32)$ and smokers $(n=10)$ using product $A$. The human figures are aligned with those obtained with smoking machines whatever the smoking behavior (puff volume, puff duration, ventilation blocked or not). 


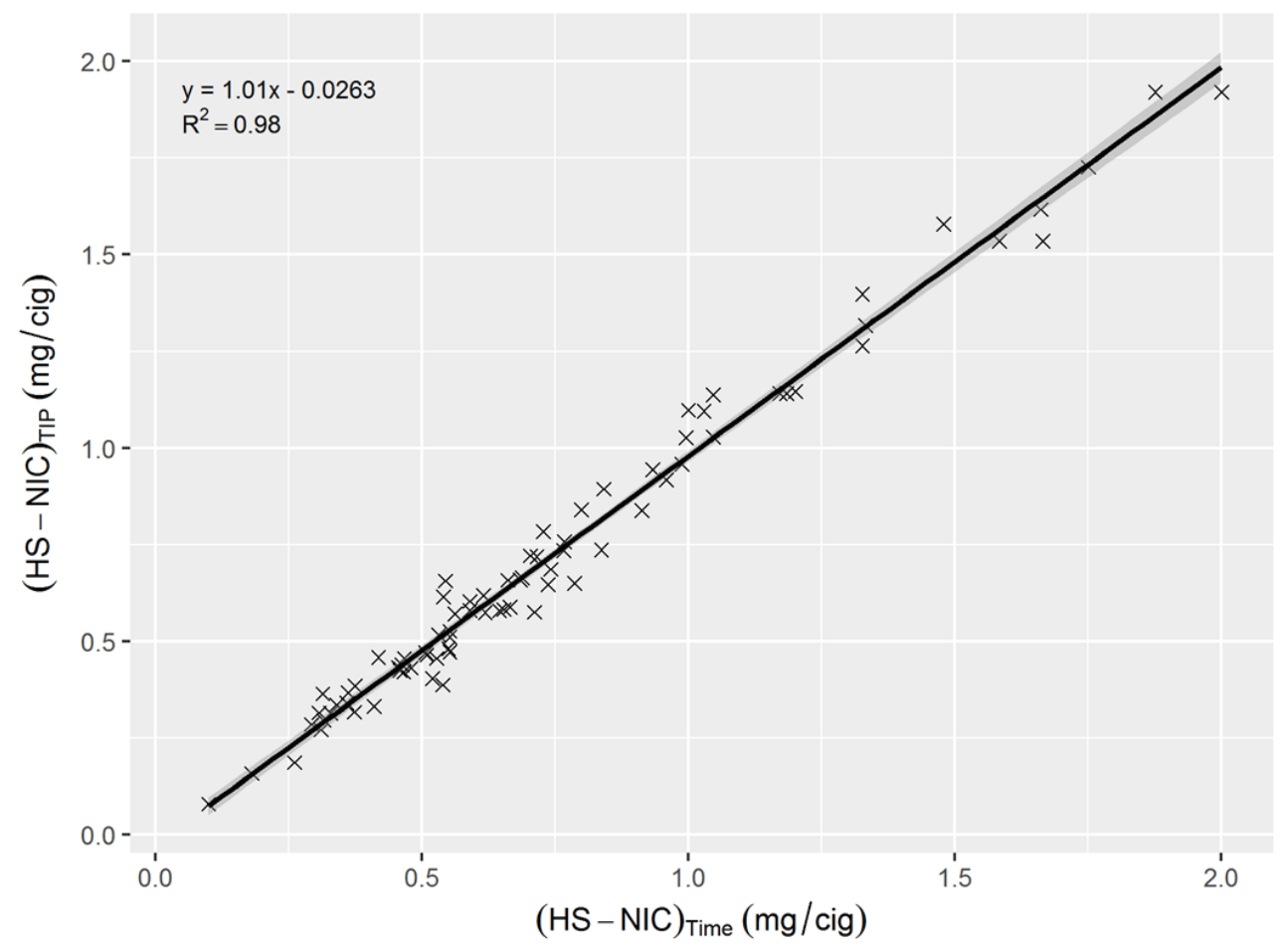

Figure 5. Human smoking nicotine yields assessed by the Part-Filter method (HS-Nic) $)_{\text {Tip }}$ versus human smoking nicotine yields assessed by the active smoking time model (HS-Nic) Time.

Therefore, HS-Nicotine yield can be estimated from the HST time and the correlation between smoking time and smoke nicotine yield obtained from a machine-smoking regime.

As demonstrated in this study, in line with the results of other publications $(22,29)$, the exposure depends essentially on the speed at which the cigarette is smoked. An increase of the human smoking intensity, resulting in a decrease in smoking time, generates an increase of smoke exposure, whatever the puff number, puff duration, puff volume and filter ventilation open or blocked. The association of a machine smoking yield with a corresponding smoking time, and the time taken by a consumer to smoke the cigarette would provide information on the exposure to smoke constituents in a simple and effective manner. This method, like the Part-Filter method, measures the nicotine mouth-level exposure, e.g., how much smoke nicotine is obtained by smokers from their cigarettes. It is the "maximum" of nicotine exposure, it does not take into account the ratio nicotine inhaled/exhaled (in-take) or the nicotine absorption (up-take). The nicotine uptake can only be assessed by measuring nicotine metabolites in biological fluids of smokers.

Table 4. HS-Nicotine of five smokers assessed with two different methods, Part-Filter and smoking time methods, and two cigarettes.

\begin{tabular}{|c|c|c|c|c|c|c|c|}
\hline \multirow[b]{2}{*}{ Smoker } & \multirow[b]{2}{*}{ Replicate } & \multicolumn{3}{|c|}{ Brand A } & \multicolumn{3}{|c|}{ Brand B } \\
\hline & & $\begin{array}{l}\text { Active HST } \\
\text { (min) }\end{array}$ & $\begin{array}{l}\text { (HS-Nic) Time } \\
\text { (mg nic/cig) }\end{array}$ & $\begin{array}{l}\text { (HS-Nic) Tip } \\
\text { (mg nic/cig) }\end{array}$ & $\begin{array}{l}\text { Active HST } \\
\text { (min) }\end{array}$ & $\begin{array}{l}\text { (HS-Nic) Time } \\
\text { (mg nic/cig) }\end{array}$ & $\begin{array}{l}\text { (HS-Nic) } \\
\text { (mg nic/cig) }\end{array}$ \\
\hline \multirow{2}{*}{1} & 1 & 1.53 & 0.63 & 0.65 & 3.00 & 1.63 & 1.68 \\
\hline & 2 & 1.41 & 0.58 & 0.60 & 3.42 & 1.86 & 1.98 \\
\hline \multirow{2}{*}{2} & 1 & 3.17 & 1.30 & 1.26 & 2.59 & 1.41 & 1.46 \\
\hline & 2 & 2.80 & 1.14 & 1.14 & 2.42 & 1.31 & 1.36 \\
\hline \multirow{2}{*}{3} & 1 & 1.42 & 0.58 & 0.59 & 1.34 & 0.73 & 0.74 \\
\hline & 2 & 1.50 & 0.61 & 0.63 & 2.19 & 1.19 & 1.22 \\
\hline \multirow{2}{*}{4} & 1 & 2.17 & 0.89 & 0.93 & 1.65 & 0.90 & 0.93 \\
\hline & 2 & 2.27 & 0.93 & 1.02 & 2.09 & 1.14 & 1.20 \\
\hline \multirow{2}{*}{5} & 1 & 0.75 & 0.31 & 0.30 & 1.42 & 0.77 & 0.79 \\
\hline & 2 & 0.76 & 0.31 & 0.32 & 1.46 & 0.79 & 0.83 \\
\hline
\end{tabular}




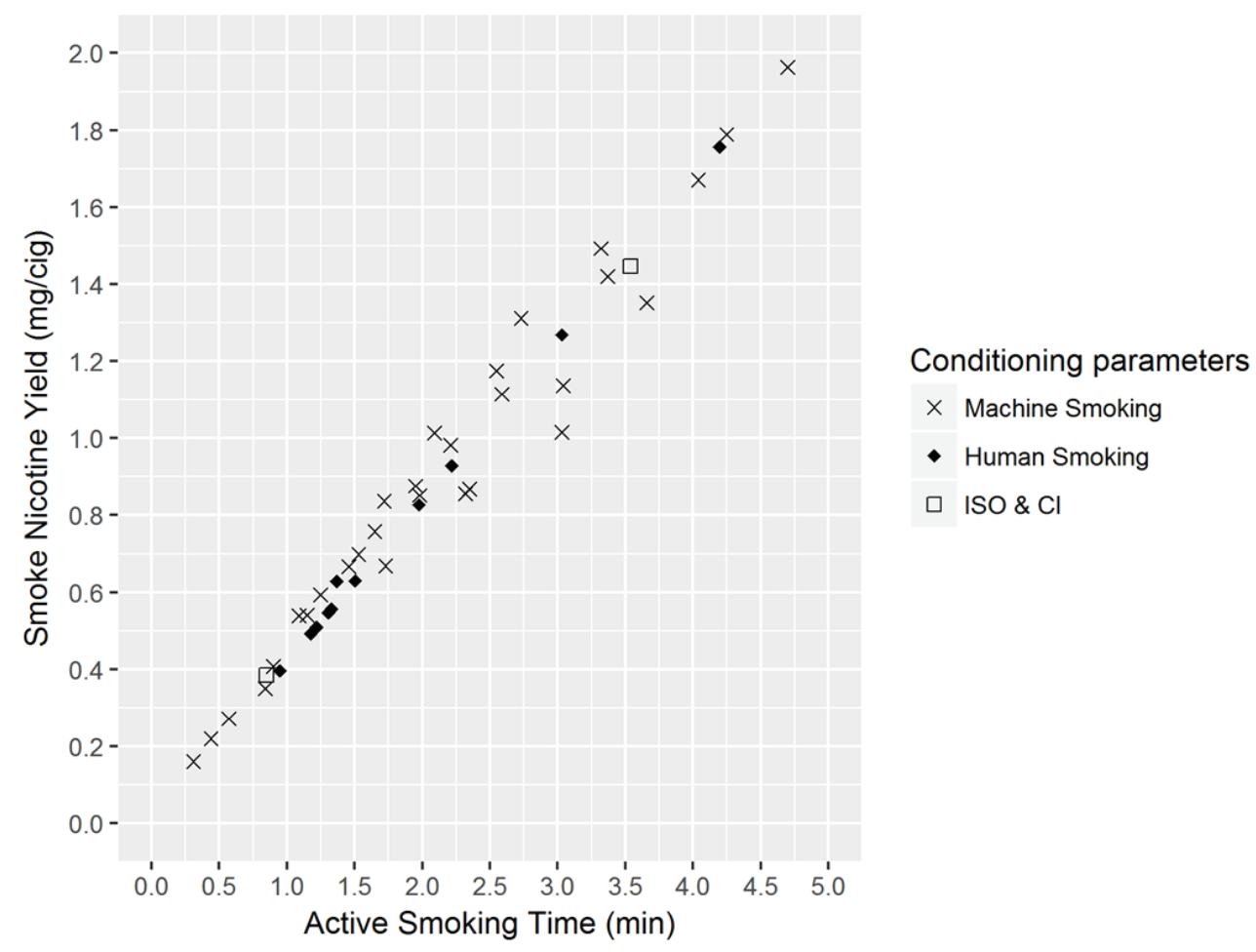

Figure 6. Relationship between smoke nicotine and active smoking time obtained with $\mathbf{3 2}$ machine smoking regimes and ten smokers using product A. Machine smoking regimes (crosses), ISO and Cl included (white squares) and smokers (black diamonds - mean of ten smoking runs).

\section{REFERENCES}

1. Jarvis, M.J., R. Boreham, P. Primatesta, C. Feyerabend, and A. Bryant: Nicotine Yield From MachineSmoked Cigarettes and Nicotine Intakes in Smokers: Evidence From a Representative Population Survey; J. Natl. Cancer Inst. 93 (2001) 134-138.

DOI: $10.1093 /$ jnci/93.2.134

2. Scherer, G., J. Engl, M. Urban, G. Gilch, D. Janket, and K. Riedel: Relationship Between Machine-Derived Smoke Yields and Biomarkers in Cigarette Smokers in Germany; Regul. Toxicol. Pharmacol. 47 (2007) 171-183. DOI: 10.1016/j.yrtph.2006.09.001

3. Hammond, D., G.T. Fong, K.M. Cummings, R.J. O’Connor, G.A. Giovino, and A. McNeill: Cigarette Yields and Human Exposure: A Comparison of Alternative Testing Regimens; Cancer Epidemiol. Biomarkers Prev. 15 (2006) 1495-1501.

DOI: 10.1158/1055-9965.EPI-06-0047

4. Mendes, P., Q. Liang, K. Frost-Pineda, S. Munjal, R. A. Walk, and H.J. Roethig: The Relationship Between Smoking Machine Derived Tar Yields and Biomarkers of Exposure in Adult Cigarette Smokers in the US; Regul. Toxicol. Pharmacol. 55 (2009) 17-27.

DOI: 10.1016/j.yrtph.2009.05.016

5. Brinkman, G.L. and E.O. Coates: The Effect of Bronchitis, Smoking, and Occupation on Ventilation; Am. Rev. Respir. Dis. 87 (1963) 684-693. DOI: 10.1164/arrd.1963.87.5.684

6. Bernaards, C.M., J.W. Twisk, J. Snel, W. van Mechelen, and H.C. Kemper: Is Calculating PackYears Retrospectively a Valid Method to Estimate
Life-Time Tobacco Smoking? A Comparison Between Prospectively Calculated Pack-Years and Retrospectively Calculated Pack-Years; Addiction 96 (2001) 1653-1661. DOI: 10.1080/09652140120080778

7. Pérez-Stable, E.J., N.L. Benowitz, and G. Marin: Is Serum Cotinine a Better Measure of Cigarette Smoking Than Self-Report?; Prev. Med. 24 (1995)171-179. DOI: 10.1006/pmed.1995.1031

8. Matsumoto, M., Y. Inaba, I. Yamaguchi, O. Endo, D. Hammond, S. Uchiyama, and G. Suzuki: Smoking Topography and Biomarkers of Exposure Among Japanese Smokers: Associations With Cigarette Emissions Obtained Using Machine Smoking Protocols; Environ. Health Prev. Med. 18 (2013) 95-103. DOI: $10.1007 / \mathrm{s} 12199-012-0293-7$

9. Mariner, D.C., M. Ashley, C.J. Shepperd, G. Mullard, and M. Dixon: Mouth Level Smoke Exposure Using Analysis of Filters From Smoked Cigarettes: A Study of Eight Countries; Regul. Toxicol. Pharmacol. 61 (2011) S39-S50. DOI: 10.1016/j.yrtph.2010.05.006

10. St.Charles, F.K., G.R. Krautter, M. Dixon, and D.C. Mariner: A Comparison of Nicotine Dose Estimates in Smokers Between Filter Analysis, Salivary Cotinine, and Urinary Excretion of Nicotine Metabolites; Psychopharmacology 189 (2006) 345-354. DOI: $10.1007 / \mathrm{s} 00213-006-0586-\mathrm{x}$

11. Morin, A., C.J. Shepperd, A.C. Eldridge, N. Poirier, and R. Voisine: Estimation and Correlation of Cigarette Smoke Exposure in Canadian Smokers as Determined by Filter Analysis and Biomarkers of Exposure; Regul. Toxicol. Pharmacol. 61 (2011) S3-S12. DOI: 10.1007/s00213-006-0586-x 
12. Pauly, J.L., R.J. O’Connor, G.M. Paszkiewicz, K.M. Cummings, M.V. Djordjevic, and P.G. Shields: Cigarette Filter-Based Assays as Proxies for Toxicant Exposure and Smoking Behavior - A Literature Review; Cancer Epidemiol. Biomarkers Prev. 18 (2009) 3321-3333. DOI: 10.1158/1055-9965.EPI-09-0925

13. St.Charles, F.K., M. Ashley, C.J. Shepperd, P. Clayton, and G. Errington: A Robust Method for Estimating Human Smoked Cigarette Yields from Filter Analysis Data; Beitr. Tabakforsch. Int. 23 (2009) 232-243. DOI: $10.2478 /$ cttr-2013-0863

14. Hyodo, T., K. Minagawa, T. Inoue, J. Fujimoto, N. Minami, R. Bito, and A. Mikita: Estimation of Mouth Level Exposure to Smoke Constituents of Cigarettes With Different Tar Levels Using Filter Analysis; Regul. Toxicol. Pharmacol. 67 (2013) 486-498. DOI: 10.1016/j.yrtph.2013.09.009

15. Nelson, P.R., P. Chen, M. Dixon, and T. Steichen: A Survey of Mouth Level Exposure to Cigarette Smoke in the United States; Regul. Toxicol. Pharmacol. 61 (2011) S25-38. DOI: 10.1016/j.yrtph.2010.10.001

16. Ashley, M., M. Dixon, A. Sisodiya, and K. Prasad: Lack of Effect of Menthol Level and Type on Smokers' Estimated Mouth Level Exposures to Tar and Nicotine and Perceived Sensory Characteristics of Cigarette Smoke; Regul. Toxicol. Pharmacol. 63 (2012) 381-390. DOI: 10.1016/j.yrtph.2012.04.010

17. Ashley, M., M. Dixon, and K. Prasad: Relationship Between Cigarette Format and Mouth-Level Exposure to Tar and Nicotine in Smokers of Russian King-Size Cigarettes; Regul. Toxicol. Pharmacol. 70 (2014) 430-437. DOI: 10.1016/j.yrtph.2014.08.002

18. Polzin, G.M., W. Wu, X. Yan, J.M. McCraw, S. Abdul-Salaam, A.D. Tavakoli, L. Zhang, D.L. Ashley, and C.H. Watson: Estimating Smokers' Mouth-Level Exposure to Select Mainstream Smoke Constituents From Discarded Cigarette Filter Butts; Nicotine Tob. Res. 11 (2009) 868-874. DOI: 10.1093/ntr/ntp080

19. Ding, Y.S., J. Ward, D. Hammond and C.H. Watson: Mouth-Level Intake of Benzo[a]pyrene From Reduced Nicotine Cigarettes; Int. J. Environ. Res. Public Health 11 (2014) 11898-11914.

DOI: $10.3390 /$ ijerph111111898

20. Ding, Y.S., T. Chou, S. Abdul-Salaam, B. Hearn, and C.H. Watson: Development of a Method to Estimate Mouth-Level Benzo[a]pyrene Intake by Filter Analysis; Cancer Epidemiol. Biomarkers Prev. 21 (2012) 39-44. DOI: 10.1158/1055-9965.EPI-11-0800

21. Zhang, X., H. Hou, L. Shi, Y. Liu, A. Wang, and Q. $\mathrm{Hu}$ : Novel Method to Analysis Benzo[a]pyrene in Filter by Liquid Chromatography/Tandem Mass Spectrometry: Application to Assess Mouth Level Benzo[a]pyrene Exposure; Rapid Commun. Mass Spectrom. 28 (2014) 1468-1472.

DOI: $10.1002 / \mathrm{rcm} .6921$

22. Liang, Q., H.J. Roethig, P.J. Lipowicz, Y. Jin and P.E. Mendes: The Effect of Cigarette Burn Time on Exposure to Nicotine and Carbon Monoxide in Adult Smokers; Regul. Toxicol. Pharmacol. 50 (2008) 66-74. DOI: 10.1016/j.yrtph.2007.08.010
23. St.Charles, F.K., A.A. Kabbani, and M.F. Borgerding: Estimating Tar and Nicotine Exposure: Human Smoking Versus Machine Generated Smoke Yields; Regul. Toxicol. Pharmacol. 56 (2010) 100-110.

DOI: 10.1016/j.yrtph.2009.08.011

24. Hammond, D., F. Wiebel, L.T. Kozlowski, R. Borland, K.M. Cummings, R.J. O’Connor, A. McNeill, G.N. Connolly, D. Arnott, and G.T. Fong: Revising the Machine Smoking Regime for Cigarette Emissions: Implications for Tobacco Control Policy; Tob. Control 16 (2007) 8-14. DOI: 10.1136/tc.2005.015297

25. International Organization for Standadarzation (ISO): ISO 10315. Cigarettes - Determination of Nicotine in Smoke Condensates - Gas-Chromatographic Method, Second Edition; ISO, Geneva, Switzerland, 2000.

26. Cooperation Centre for Scientific Research Relative to Tobacco (CORESTA): CORESTA Recommended Method No. 9: Determination of Nicotine in Cigarette Filters by Gas Chromatographic Analysis; 2009. Available at: https://www.coresta.org/sites/default/ files/technical_documents/main/CRM_09-update2.pdf (accessed August 2017)

27. Colard, S., T. Verron, R. Julien, X. Cahours, and S.W. Purkis: Relationship Between Cigarette Yields and Smoking Time Under Different Machine Smoking Regimes; Beitr. Tabakforsch. Int. 26 (2014) 4-18. DOI: $10.2478 /$ cttr-2014-0003

28. Colard, S.: Prediction Model for Cigarette Yields Derived from Data Obtained under Two Different Machine Smoking Regimes; Beitr. Tabakforsch. Int. 26 (2015) 320-333. DOI: 10.1515/cttr-2015-0022

29. Benowitz, N.L., P. Jacob III, and B. Herrera: Nicotine Intake and Dose Response When Smoking ReducedNicotine Content Cigarettes; Clin. Pharmacol. Ther. 80 (2006) 703-714. DOI: 10.1016/j.clpt.2006.09.007

\section{Corresponding author:}

Xavier Cahours, Ph.D.

SEITA Imperial Tobacco Ltd. 48, rue Danton

45404 Fleury-les-Aubrais, France

E-mail:xavier.cahours@fr.imptob.com 
Appendix. Abbreviations and definition of terms.

\begin{tabular}{|c|c|}
\hline Term & Definition \\
\hline Cigarettes per day (CPD) & Number of cigarettes smoked per day \\
\hline Brinkman index $(\mathrm{BI})$ & Number of cigarettes smoked per day multiplied by number of years of smoking \\
\hline Pack years $(P Y)$ & $\begin{array}{l}\text { The number of years of smoking multiplied by the number of packs of cigarettes } \\
\text { smoked per day }\end{array}$ \\
\hline Smoke exposure & $\begin{array}{l}\text { Concentration multiplied by the time for a specified constituent present in the smoke } \\
\text { (such as nicotine) }\end{array}$ \\
\hline Biomarker of exposure (BOE) & $\begin{array}{l}\text { A smoke constituent or its metabolite that is measured as a concentration in body } \\
\text { fluids }\end{array}$ \\
\hline Intake & $\begin{array}{l}\text { The mass or fraction of a specific smoke constituent (such as nicotine) that is taken } \\
\text { into the respiratory system, prior to any deposition or absorption }\end{array}$ \\
\hline Uptake & $\begin{array}{l}\text { The amount of smoke constituents (such as nicotine) which is absorbed into the } \\
\text { body }\end{array}$ \\
\hline Machine smoking (MS) yield & $\begin{array}{l}\text { Amount of a given mainstream smoke constituent (such as nicotine) exiting the } \\
\text { cigarette under machine smoking conditions at a specified smoking regime }\end{array}$ \\
\hline Human smoking (HS) yield or mouth-level exposure & $\begin{array}{l}\text { Amount of a given mainstream smoke constituent (such as nicotine) exiting the } \\
\text { cigarette into the mouth, when a given person smokes a cigarette }\end{array}$ \\
\hline Puffing topography & $\begin{array}{l}\text { The complete pattern using a cigarette, including puffing, mouth hold, inhalation } \\
\text { and exhalation }\end{array}$ \\
\hline Smoking topography & $\begin{array}{l}\text { The complete pattern using a smoking article, including puffing, mouth hold, } \\
\text { inhalation and exhalation }\end{array}$ \\
\hline Machine smoking time (MST) & $\begin{array}{l}\text { The time a cigarette burns during smoking under machine smoking conditions at a } \\
\text { specified smoking regime }\end{array}$ \\
\hline Smouldering time & The time a cigarette burns with no puffing \\
\hline Active machine smoking time (Active MST) & The smouldering time minus machine smoking time \\
\hline Human smoking time (ST) & The time a cigarette burns during smoking, when a given person smokes cigarette \\
\hline Active smoking time (Active ST) & The smouldering time minus human smoking time \\
\hline
\end{tabular}

